\title{
A IMPORTÂNCIA DA BRINQUEDOTECA NA EDUCAÇÃO INFANTIL
}

\author{
Carmen Gonçalina da Silva ${ }^{1}$ \\ Dasny Pestana de Pinto ${ }^{2}$ \\ Jucilene Pinto de Campos ${ }^{3}$ \\ Thelma Auxiliadora Silva de Jesus Resende 4 \\ Vanildes Célia de Paula ${ }^{5}$
}

RESUMO: O presente artigo tem como tema a brinquedoteca, buscou-se demonstrar sua importância nas instituições de Educação Infantil. $\mathrm{Na}$ medida em que a sociedade se transforma, o ritmo acelerado de trabalho, as mudanças ocorridas nas relações familiares, o brincar acaba não tendo valor, nem espaço, nesse momento de grandes mudanças, as instituições de Educação Infantil podem criar alternativas para minimizar essas consequências para a vida das crianças. Portanto nesse cenário, acredita-se que seria muito interessante inserir nos espaços institucionais, as brinquedotecas, que são espaços organizados de maneira a permitir que as crianças brinquem e desenvolvam, suas habilidades psicomotoras, sua cidadania e socialização, entre outros aspectos.

Palavras-chave: Brinquedoteca. Educação Infantil. Ensino-aprendizagem.

ABSTRACT: This article has as its theme the toy library, and sought to demonstrate its importance in early childhood education institutions. As society changes, the accelerated pace of work, the changes that have occurred in family relationships, playing ends up having no value or space, at this time of great changes, Early Childhood Education institutions can create alternatives to minimize these consequences for children's lives. Therefore, in this scenario, it is believed that it would be very interesting to include in institutional spaces, the toy libraries, which are spaces organized in order to allow children to play and develop their psychomotor skills, their citizenship and socialization, among other aspects.

Keywords: Toy library. Child education. Teaching-learning.

\footnotetext{
I Graduada em Pedagogia pela Faculdade Educacional - FAEL, Especialista em Educação Infantil pelas Faculdades Integradas de Várzea Grande - FIAVEC.

${ }^{2}$ Graduada em Pedagogia - Docência para a Educação Infantil e Anos Iniciais do Ensino Fundamental e na Empresa pelo UNIVAG - Centro Universitário, Especialista em Educação Infantil pela Faculdade Mantenense dos Vales Gerais - INTERVALE.

3 Graduada em Pedagogia pela Faculdade Afirmativo.

${ }_{4}$ Graduada em Pedagogia pela UNIP - Universidade Paulista, Especialista em Educação Infantil com Ênfase em Educação Especial pela UniSerra - Faculdade de Educação de Tangará da Serra.

5 Graduada em Pedagogia pela Faculdade Mantenense dos Vales Gerais - INTERVALE, Especialista em Educação Infantil e as Séries Iniciais do Ensino Fundamental pela Faculdade Integrada de Ariquemes.
} 


\section{INTRODUÇÃO}

As crianças pequenas, para poderem crescer e aprender precisam de tempos e espaços destinados as brincadeiras. No entanto, o modo como as cidades são organizadas, fazem com que o trabalho dos adultos seja cada vez mais distante de suas residências, perdem assim muito tempo no trânsito, normalmente ao finalizarem esse trajeto chegam em cansados, desanimados para brincarem com seus filhos, perdendo momentos de brincadeiras do cotidiano infantil.

As brinquedotecas, objeto deste artigo, surgem como possíveis espaços para as crianças brincarem, uma vez que a sociedade tem se organizado em função dos adultos e dos processos produtivos e pouco tempo lhes são direcionados pelos adultos para as brincadeiras.

Para desenvolver o estudo foram selecionadas publicações que contemplam as crianças pequenas como sujeitos de direitos, participantes de uma determinada cultura e que têm no brincar uma de suas maiores necessidades. A revisão bibliográfica também buscou compreender o momento histórico no qual surgiram as brinquedotecas, quais as suas características, os seus objetivos e as possíveis contribuições para as crianças que frequentam as instituições de Educação Infantil.

A sociedade passa por um momento de grandes transformações tecnológicas e sociais e no mesmo ritmo tem aumentado a violência no país, de forma que as crianças passam a não ter mais a possibilidade de brincarem e se desenvolverem em brincadeiras coletivas ou individuais ao ar livre. Ao passo que a sociedade se transforma, os ritmos de trabalho e os hábitos familiares mudam, e nesse momento de grandes transformações, a escola pode criar uma alternativa para minimizar as consequências maléficas desses avanços para as crianças.

Nesse cenário, acredita-se que as escolas inserissem em seus espaços as brinquedotecas, que são espaços organizados que permitem que as crianças brinquem e se desenvolvam tanto no que diz respeito às habilidades psicomotoras, assim como no respeito à cidadania e socialização.

$\mathrm{Na}$ Brinquedoteca, o potencial e habilidades das crianças surgem de modo natural, uma vez que elas não são forçadas a realizarem atividades que não gostam, ou que não lhes são interessantes, favorecendo a ludicidade, tão importante para a saúde mental do ser 
humano, resgatando um espaço para a expressão mais genuína do ser, é o espaço do exercício da relação afetiva com o mundo, com as pessoas e com os objetos.

A presente pesquisa, deseja abordar o assunto "brinquedoteca" de tal forma que seja possível compreender as contribuições da mesma no processo de ensino-aprendizagem na Educação Infantil.

Para a realização do presente artigo, foi utilizado a pesquisa bibliográfica relacionada à brinquedoteca nos ambientes escolares e suas contribuições no processo de ensino e aprendizagem de crianças da Educação Infantil.

\section{DESENVOLVIMENTO}

\section{I Breve histórico da brinquedoteca}

A história relata que a Brinquedoteca surgiu com diversas denominações tais como: Toy-Library (biblioteca de brinquedo), na Inglaterra; Ludothéque, na França; Lekoteks na Suécia; no Brasil Brinquedoteca ou Ludoteca, sob influências portuguesas que se instalaram em diversas partes do mundo.

De acordo com a (ABBri) Associação Brasileira de Brinquedotecas, a primeira intenção de Brinquedoteca surgiu em 1934, em Los Angeles, nos Estados Unidos da América (EUA) num momento de crise econômica e com o objetivo de solucionar problemas causados por frequentes roubos em sua loja de brinquedos. O proprietário relatou ao diretor da instituição de ensino municipal sobre os desvios de comportamentos dos alunos daquela instituição no seu estabelecimento comercial. Foi então que o diretor da escola, partindo de um problema constatou que os acontecimentos desta natureza (roubos) eram decorrentes devido à escassez de brinquedos às crianças que lá estudavam. Deste modo, o diretor da instituição criou a primeira intenção de Brinquedoteca, dispondo aos alunos, neste espaço, brinquedos variados onde as mesmas poderiam explorá-los in loco (LIMA \& DELMÔNICO, 20I0).

No Brasil, a brinquedoteca surgiu em 197ı, quando foi realizada uma exposição de brinquedos pedagógicos, direcionados aos pais de crianças ditas excepcionais, aos profissionais e aos estudantes, mais especificamente no Centro de Habilitação da Associação 
de Pais e Amigos dos Excepcionais (APAE), em São Paulo. A adesão ao projeto tomou proporções tão significativas que a (APAE) criou um Setor de Recursos Pedagógicos para atender o público, ou seja, instituiu uma ludoteca nesta instituição, que objetivava a circulação de brinquedos entre as crianças.

A brinquedoteca surgiu com objetivos educacionais e terapêuticos, que obtinha o apoio tanto do setor público, como privado para o funcionamento e atendimento às crianças que visitavam o espaço educacional.

É garantido na Constituição Federal de 1988, no capítulo III - Da Educação, Da Cultura e Do Desporto, no artigo 205 que: “A educação, direito de todos e dever do Estado e da família, será promovida e incentivada com a colaboração da sociedade, visando ao pleno desenvolvimento da pessoa, seu preparo para o exercício da cidadania e sua qualificação para o trabalho".

O artigo 29 da lei 9394/96 diz que "a Educação Infantil, primeira etapa da Educação básica, tem como finalidade o desenvolvimento integral da criança até seis anos de idade, em seus aspectos físicos, psicológicos, intelectual e Social, complementando a ação da família e da comunidade”.

A Educação é um direito e a formação para a cidadania e para o trabalho dependem muito das estratégias utilizadas pelos ambientes escolares desde a Educação Infantil, nas pré-escolas e creches.

Conforme Oliveira (2007, p. 47), “os cuidados ministrados na creche e na pré-escola não se reduzem ao atendimento de necessidades físicas das crianças, deixando-as confortáveis em relação ao sono e, à fome, à sede e à higiene. Incluem a criação de um ambiente que garanta segurança física e psicológica delas, que lhes assegure oportunidades de exploração e de construção de sentidos pessoais, que se preocupe com a forma pela qual elas estão se percebendo como sujeitos”. “[...] Crianças são aquelas "figurinhas” curiosas e ativas, com direitos e necessidades, que precisam de um espaço diferente tanto no ambiente familiar, onde são objeto do afeto de adultos (em geral, adultos muito confusos), quanto do ambiente escolar tradicional, frequentemente orientado para a padronização de conduta e ritmos e para avaliações segundo parâmetros externos à criança”. 
A sociedade tem se organizado de tal forma, que cada vez menos as crianças brincam, o que vem acarretando em várias mudanças de hábitos e comportamentos na sociedade como um todo. Os pais, muitas vezes não tem tempo para brincar com seus filhos, nem a oportunidade de levá-los a ambientes organizados para que usem a imaginação, a criatividade, se movimentem, criem, etc., tornando assim as crianças mais limitadas em suas capacidades criativas.

De acordo com Oliveira (2007): “ [...] o ambiente das creches e pré-escolas pode ser considerado como um campo de vivências e exploração, zona de múltiplos recursos e possibilidades para a criança reconhecer objetos, experiências, significado de palavras e expressões, além de ampliar o mundo de sensações e percepções”.

\subsection{A importância da brinquedoteca para o desenvolvimento humano}

Ao falamos em brinquedoteca, logo pensamos em crianças, lúdico, brincar, brinquedo e brincadeira, ou seja, em atividades que possibilitam às crianças o desenvolvimento: cognitivo, motor, social ou afetivo. Ao brincar as crianças interagem umas com as outras, estimulando assim sua criatividade, autoconfiança, autonomia e curiosidade, resultando em uma maturação no que diz respeito a aquisição de novos conhecimentos.

Objetivando o resgate do brincar espontâneo como elemento essencial para o desenvolvimento integral da criança, de sua criatividade, aprendizagem e socialização é que surgem as brinquedotecas (ludotecas) (MAGALHÃES \& PONTES, 2002).

A Brinquedoteca é "responsável por mediar à construção do saber, em situações de prazer, com gosto de aventura, na busca pelo conhecimento espontâneo e prazeroso", e incentiva extravasar sentimentos, conhecimentos e emoções (CUNHA apud LIMA et al, $\mathrm{s} / \mathrm{d})$.

De acordo com SILVA et al (s/d), "na brinquedoteca, as potencialidades e habilidades das crianças são despertadas e desenvolvidas de maneira natural, sem força-las a atividades que não gostam ou que não lhe despertam interesse".

De acordo com Santos (1995), existem alguns objetivos que são muito importantes ao desenvolvimento pessoal das crianças nas brinquedotecas tais como:

- Valorizar o ato de brincar de forma espontânea; 
- Resgatar o espaço e o tempo de brincar;

- Possibilitar o acesso a brinquedos;

- Orientar sobre a adequação e utilização dos brinquedos;

- Desenvolver hábitos de responsabilidade;

- Resgatar brincadeiras, incentivando sua valorização como atividade geradora de desenvolvimento intelectual, emocional e social;

- Propiciar a construção de conhecimentos;

- Estimular o desenvolvimento da concentração e atenção;

- Oportunizar a expansão de habilidades e potencialidades;

- Desenvolver a criatividade, a sociabilidade e a sensibilidade;

- Incentivar a autonomia e o sentimento de autoestima;

- Repassar aos professores e às famílias informações sobre conhecimentos a respeito da importância do brincar e sobre o desenvolvimento de cada criança.

Carvalho, Alves \& Gomes (2005) apud Dytz \& Cristo (1995) destacaram a importância da ludoteca como local de brincadeiras nas instituições infantis. Ela é um espaço privilegiado de brincadeiras que estimula a imaginação, a fantasia e a compreensão do mundo por parte da criança.

$\mathrm{Nas}$ brinquedotecas, o potencial e as habilidades das crianças afloram de maneira brincante, uma vez que elas não são forçadas a realizarem atividades que não gostam, ou que não lhes são interessantes. Esses espaços e esses tempos favorecem a ludicidade, tão importante para a saúde mental do ser humano, resgatando um espaço para a expressão mais genuína do ser. São espaços e tempos propícios para o exercício das relações afetivas com as pessoas, com os objetos, com o mundo.

Conforme Costa (20II), as brinquedotecas pedagógicas objetivam suprir as necessidades materiais que promovam o desenvolvimento da aprendizagem, sendo organizadas principalmente em escolas de educação infantil em um setor da escola onde os alunos possam brincar e escolher os jogos e brinquedos.

Nessa concepção, nos ambientes das brinquedotecas, o brincar supre algumas necessidades das crianças, tais como: expressar, participar, transformar, desenvolver, aprender e atuar com subjetividade no cotidiano escolar, na sociedade e na sua cultura. 
Diante desse propósito, torna-se primordial refletir sobre a sua importância da mesma nas instituições de Educação Infantil como espaços mediadores de aprendizagens, como locais voltados para brincadeiras sob a coordenação de professoras, mas sem diretividade, assegurando a cada criança explorar os espaços e os objetos nos seus tempos e de acordo com as suas escolhas.

A Brinquedoteca, como espaço de brincar livre, diferencia-se da escola infantil que tem a função educativa como sua finalidade. As instituições formais de Educação Infantil não compreenderam que a educação de qualidade se inicia com a observação da criança, de seu brincar livre, para planejar ações pedagógicas (KISHIMOTO \& ONO, 2008).

Um espaço apropriado para a atividade lúdica como a Brinquedoteca com profissionais competentes, permitirá a criança um maior desenvolvimento afetivo, ao interagir com outras crianças através de brincadeiras, o companheirismo, a disciplina, como ao guardar o brinquedo após usá-lo, no comportamento, na sociabilidade, a criatividade, enfim, permite uma "liberdade" ao aprender brincando.

[...] A Brinquedoteca favorece a ludicidade, tão importante para a saúde mental do I8 ser humano, resgatando um espaço para a expressão mais genuína do ser, é o espaço do exercício da relação afetiva com o mundo, com as pessoas e com os objetos. (SILVA et al, $\mathrm{s} / \mathrm{d})$.

A Brinquedoteca não tem limitações quanto ao público alvo a ser atendido, mas, sua presença na escola contribui em muito como espaço fundamental para o desenvolvimento das brincadeiras lúdicas, com diversidade de propostas e objetivos ilimitados e flexíveis, atendendo aos interesses e a realidade do ambiente de inserção, e é na escola que a criança permanece a maior parte do dia, sendo este também, um espaço social de ressignificação da aprendizagem, que deve permitir e estimular um resgate do direito à infância a conquista da liberdade de escolha e, conscientemente, a conquista do seu mundo através da ludicidade, que vem sendo privada na vida das pessoas devido à contemporaneidade. Para Vieira (2010), a Briquedoteca é uma forma de se utilizar o lúdico como uma fonte de aprendizagem, faz uso de um ambiente que também propicie isso, com cores, formas, desenhos, objetos, que ao entrar em contato, crianças, jovens e adultos 


\subsection{O brinquedo, o brincar e a brincadeira}

A importância do brincar foi reconhecida mundialmente, conforme descrito no Princípio $7^{\circ}$ da Declaração Universal dos Direitos da Criança, (1959 s/p.) cujo texto diz: "A criança deve ter plena oportunidade para brincar e para se dedicar a atividades recreativas, que devem ser orientadas para os mesmos objetivos da educação; a sociedade e as autoridades públicas deverão esforçar-se por promover o gozo destes direitos" (LIMA \& DELMÔNICO, 2010). Brincar é indispensável ao desenvolvimento infantil pois brincando, podem resolver conflitos, viver suas tristezas e alegrias, aprender a conviver, a reivindicar, a ceder. Por meio do brinquedo, brincadeiras, do lúdico de maneira geral, a criança descobre suas emoções e a existência do outro, suas possibilidades e limitações e ainda tem estimulada a cooperação, a autoestima e o autocontrole.

O brincar para a criança é coisa séria. Brincando vai desempenhando vários papéis sociais, representando sua realidade (HYPOLITTO, 200I). Brincar é o ponto fundamental para o desenvolvimento de uma aprendizagem que valorize o desejo de aprender e tendo a criança como um ser integral” (FRIEDMANN apud SILVA et al, s/d).

Para Mafra (2008), o brincar estimula a curiosidade, a iniciativa e a autoconfiança. Também proporciona aprendizagem, desenvolvimento da linguagem, do pensamento, da concentração e da atenção. Os jogos e brincadeiras são estimuladores da cognição, afeição, motivação e criatividade.

Carvalho, Alves \& Gomes (2005) apud Ortega \& Rosseti (2000) colocam que o uso do brincar permite a articulação entre os processos de ensino e da educação e exige uma postura ativa por parte do educando, que articula o ensino e a aprendizagem em um único movimento. Assim, a inserção do brincar livre, espontâneo, no currículo educacional e, consequentemente, nos projetos pedagógicos das instituições educativas, é um processo de transformação política e social em que crianças são vistas pelos educadores como cidadãs, isto é, cada uma como sujeito histórico e sociopolítico, que participa e transforma a realidade em que vive.

Gusso \& Schuartz (2005), o brincar pode promover a construção do conhecimento, pois o brinquedo apresenta uma função social, uma vez que permite o processo de apreensão, análise, síntese, expressão e comunicação da criança sobre si mesma e o mundo que a rodeia, 
criando um sentimento e uma identidade pessoal e social, de pertencer e interagir em uma determinada realidade, evoluindo progressivamente da auto-esfera (egocentrismo) à macroesfera (socialização).

É brincando, propondo jogos que a criança irá aprender, pois são atividades interessantes que despertam a curiosidade e o prazer em construir conhecimentos, interagindo com o meio físico e social. Portanto, é importante valorizá-lo, dando o tempo para que as crianças possam expressar-se ludicamente aflorando sua criatividade, fantasias, sonhos, frustrações, passando a agir e lidar com seus pensamentos e emoções de forma espontânea. 20

Conforme Vygotsky (20II) “É enorme a influência do brinquedo no desenvolvimento de uma criança”. [...] "Na idade pré-escolar ocorre, pela primeira vez, uma divergência entre os campos do significado e da visão. No brinquedo o pensamento está separado dos objetos, e a ação surge das ideias e não das coisas: um pedaço de madeira tornase um boneco, e um cabo de vassoura torna-se um cavalo”. A criança vivencia a experiência no brinquedo como se ela fosse maior do que é, na realidade, fator de grande importância no seu desenvolvimento. Brincando a criança elabora hipóteses para a resolução dos problemas e toma atitudes além do comportamento habitual de sua idade (VYGOTSKY apud LIMA, 2006).

O desenvolvimento da criança é constante e o brinquedo permite a ela, principalmente o desenvolvimento de sua imaginação e criatividade. A partir dos brinquedos, a criança tem inúmeras possibilidades imaginativas tanto de fatos $\mathrm{e}$ circunstâncias relacionadas ao seu dia a dia como também fatos abstratos ou importantes especificamente para a brincadeira.

Para Vygotsky (1998) apud Mafra (2008), é enorme a influência do brinquedo no desenvolvimento de uma criança. No brinquedo, o pensamento está separado dos objetos e a ação surge das ideias e não das coisas: um pedaço de madeira torna-se um boneco e um cabo de vassoura torna-se um cavalo. O brinquedo é um fator muito importante nas transformações internas do desenvolvimento da criança.

A brincadeira favorece o equilíbrio afetivo da criança e contribui para o processo de apropriação de signos sociais. Cria condições para uma transformação significativa da 
consciência infantil, por exigir das crianças formas mais complexas de relacionamento com o mundo. Isso ocorre em virtude das características da brincadeira: a comunicação interpessoal que ela envolve não pode ser levada "ao pé da letra", sua indução a uma constante negociação de regras e à transformação dos papéis assumidos pelos participantes faz com que seu enredo seja sempre imprevisível (OLIVEIRA, 2007, p. 160).

A brincadeira não é o brinquedo, o objeto, e também não é a técnica, mas um conjunto de procedimentos e habilidades. A brincadeira possibilita, sempre uma experiência original, reveladora, única, mesmo que as crianças estejam repetindo a brincadeira pela milésima vez. A brincadeira é a plena realização da imprevisibilidade (MATUSHITA \& MENDES, s/d).

\subsection{A importância das atividades lúdicas}

Atividade lúdica é todo e qualquer movimento que tem como objeto em si mesmo, produzir prazer desde a sua execução, ou seja, divertir o praticante. A ludicidade não é apenas divertimento, ou um brincar por brincar é algo que deve ser trabalhado pelo educador. Piaget afirma: “os jogos não são apenas uma forma de desafogo ou entretenimento para gastar a energia das crianças, mas meios que enriquecem o desenvolvimento intelectual" (PIAGET apud SILVA et al, s/d).

De acordo com Cavallari \& Zacharias (2008), as atividades lúdicas devem adequarse à faixa etária das crianças, para que contemplem as suas possibilidades e características.

$\mathrm{Na}$ sociedade de forma geral, ainda existem muitas pessoas que menosprezam a importância do lúdico para a criança, mas estão completamente equivocadas, já que a partir do lúdico a criança fica em sala de aula atenta por mais tempo nas atividades propostas e consequentemente aprendem mais e melhor. Quando a criança faz algo que ela gosta, internaliza as suas ações e isso lhe resulta em grandes satisfações.

Quando falamos em lúdico, nos remetemos a atividades diferentes das tradicionais, em atividades divertidas, descontraídas e ampla no que diz respeito a fatores de aprendizagem, pois leva a criança a interagir com colegas ou outras pessoas, desenvolve seu senso de cidadania, eleva sua criatividade e senso crítico, entre outros fatores. O lúdico desperta na criança o prazer em fazer parte de determinada atividade e ainda desenvolve nela a capacidade de organização do pensamento, sendo que ela passa a ter momentos de 
fantasia e ficção fazendo parte de sua vida, mas ao mesmo tempo, também consegue identificar o que é real. É uma forma leve e eficaz de fazer com que a criança ao mesmo tempo que se diverte, também aprende.

Piaget (1975) apud Mafra (2008), valoriza a prática lúdica para que o desenvolvimento infantil seja harmonioso, pois tal atividade propicia a expressão do imaginário, a aquisição de regras e a apropriação do conhecimento.

A brinquedoteca vem completamente ao encontro a essas possibilidades para as crianças aprenderem, já que lá existem jogos, brinquedos e brincadeiras possíveis que o faça a se remeter ao seu próprio cotidiano, às suas próprias experiências de vida.

A atividade lúdica fornece às crianças um maior e melhor desenvolvimento, seja ele cognitivo, motor, social ou afetivo, pois a criança ao brincar interage com outras crianças, estimulando a criatividade, a autoconfiança, a autonomia e a curiosidade, devido à situação de certos jogos e brincadeiras, o que garante uma maturação na aquisição de novos conhecimentos (SILVA et al, s/d).

\subsection{A educação e a sociedade contemporânea}

A educação das crianças pequenas, nas sociedades urbanas contemporâneas, torna-se cada vez mais complexa para as famílias que, de maneira geral, não possuem mais os tempos e os espaços necessários para a convivência.

Nesse contexto, quando as crianças passam a participar da Educação Infantil, elas precisam de tempo e espaço para desenvolver as atividades escolares e construir boas relações sociais com as demais crianças e adultos que trabalham na escola. Por meio dessas interações, as crianças podem desenvolver novas habilidades de formação de amizade por meio de brincadeiras em grupo, melhorando assim o desenvolvimento psicológico e social. Eles também podem construir um estilo de vida saudável quando estimulados e orientados.

Os avanços tecnológicos e a nova organização do convívio social nas cidades, o medo à violência e o trabalho dos responsáveis, cada vez mais distante e em períodos mais longos de tempo, tem afastado as brincadeiras do cotidiano infantil, tornando as crianças menos ativas e carentes de um ambiente próprio para a descontração e as aprendizagens. Além disso, em geral, devido à facilidade de preparo, adultos e crianças que passam a consumir 
lanches e bebidas, o resultado desses hábitos é o aumento da prevalência da obesidade, associado aos confortos da vida moderna.

Carneiro (2008, p. I) apud Lima \& Delmônico (2010) “as brincadeiras voltam-se para o individualismo e a competitividade, o uso dos brinquedos eletrônicos, a televisão passou a disputar a atenção das crianças", acarretando problemas de sociabilização, integração e interação entre as pessoas, e principalmente entre as crianças.

A população diminui os hábitos relacionados às práticas corporais e, diminuindo-as, não conseguem queimar as energias consumidas diariamente com excesso de frituras e gorduras. Isso tudo acaba por levar a população em geral, assim como as crianças, a desequilíbrios metabólicos, a obesidade, a problemas de hipertensão, entre outros.

Conforme Varella (2006) a obesidade infantil é uma doença de consequências graves que se instalam em múltiplos órgãos. $\mathrm{O}$ excesso de gordura corpórea na infância pode causar hipertensão, diabete, elevação dos níveis de triglicérides e colesterol, coagulação acelerada do sangue, entre outros.

Nesse contexto, quando as crianças pequenas passam a frequentar as instituições educativas de Educação Infantil precisam de tempo e espaço para desenvolver as atividades escolares e construir boas relações sociais com outras crianças e adultos que trabalham na escola. Por meio dessas interações, as crianças podem desenvolver habilidades para formar novas amizades durante as brincadeiras em grupo, melhorando assim as habilidades psicomotoras e o desenvolvimento social. Eles também podem adotar um estilo de vida saudável com estímulo e orientação.

De acordo com Magalhães \& Pontes (2002) “ Resgatar o espaço, meio e o tempo para as crianças brincarem espontaneamente é, sem dúvida, um dos nossos maiores compromissos e desafios atuais".

Portanto, a brinquedoteca é um espaço que nos permite resgatar a vivencia do lúdico esquecidas e negadas nos tempos modernos. Seu trabalho é fazer as crianças felizes, que é o objetivo mais importante. Com isso, esse espaço de aprendizagem permite que os alunos construam diferentes identidades, autonomia e linguagens. É “responsável por mediar à construção do saber, em situações de prazer, com gosto de aventura, na busca pelo 
conhecimento espontâneo e prazeroso", e incentiva extravasar sentimentos, conhecimentos e emoções (CUNHA apud LIMA et al).

Para Oliveira (2007), a brincadeira permite que as crianças desenvolvam novas capacidades de comportamento e organização de novos elementos ambientais. Os objetos usados na brincadeira são usados simbolicamente por meio de elementos de postura, expressão, gestos verbais e imitação, e o ambiente faz parte do cotidiano da criança. Os objetos usados na brincadeira são usados simbolicamente, imitando gestos e posturas, expressões e palavras.

A brincadeira permite que as crianças desenvolvam novas habilidades comportamentais e novas formas de organizar os elementos do ambiente. Os objetos usados nas brincadeiras são usados simbolicamente, imitando as posturas, expressões e palavras que fazem parte do cotidiano da criança por meio de gestos (OLIVEIRA, 2007).

\section{CONCLUSÃO}

A Educação Infantil como um todo é uma categoria educacional da educação básica, que particularmente nos atrai, nos desperta muita curiosidade e desejo de saber mais, nos permite como professoras atuar como de modo mais preciso em relação a prática docente.

A ludicidade orienta as crianças para um aprendizado fácil, liberando-as para imaginar, meditar, brincar e se divertir. Por meio da ludicidade, os professores podem reconhecer diferentes atitudes, comportamentos, maneiras e até expressões físicas nos alunos que representam como o aluno vê o mundo naquele momento.

Nesse ponto, ele pode fingir e lidar com sua situação diária, estando feliz ou não. A forma como soa e se apresenta é um forte indicador para os professores adotem melhores métodos de ensino, afim de responder melhor às suas necessidades em um processo de ensino e aprendizagem eficaz.

A ludicidade, o brincar e o brincar são a base de um bom desenvolvimento para crianças de 2 a 5 anos e em aspectos como uma brinquedoteca que permite às crianças brincarem e se divertirem sem compromisso com jogos mais holísticos, mas os professores podem observar e analisar o comportamento dos alunos para compreender melhor seus alunos. 
Para amenizar os efeitos dessas mudanças e preocupações, é possível criar brinquedotecas e outros espaços no ambiente escolar para que as crianças possam brincar livremente e sem medo.

Enquanto brincam e se divertem, as crianças se deparam com muitas situações importantes que podem superar as vividas e causar algum tipo de sofrimento. Ao brincar aprende a se conhecer, cria mecanismos de defesa.

\section{REFERÊNCIAS}

ABBRI - Associação Brasileira de Brinquedotecas. Histórico. Disponível em http://www.brinquedoteca.org.br/si/site/o022000/p. Acesso em 28/o7/2021.

CARVAlhO, A. M.; ALVES, M. M. F.; GOMES, P. de L.D. Brincar e Educação: Concepções e finalidades. Disponível em http://www.scielo.br. Acesso em 28/o7/202I.

CAVALLARI, V. R. ZACHARIAS, V. Trabalhando com recreação. Ícone, 2008.

COSTA, A. G. da. A brinquedoteca como um recurso de intervenção terapêutica e de convívio sócio afetivo. Disponível em http://www.soartigos.com. Acesso em 28/o7/2021.

GUSSO, S. de F. K; SCHUARTZ, M. A. A criança e o lúdico: A importância do Brincar. Disponível em http://www.pucpr.br. Acesso em 28/o7/2021.

HYPOLITTO, D. Brinquedoteca. Disponível em http://www.usjt.br. Acesso em 28/07/2021.

KISHIMOTO, T. M.; ONO, A. T. Brinquedo, gênero e educação na brinquedoteca. Disponível em http://www.scielo.br. Acesso em 28/o7/2021.

LIMA, J. da S. A importância do brincar e do brinquedo para crianças de três e quatro anos na educação infantil. Pedagogia em Foco, Rio de janeiro, 2006. Disponível em http://www.pedagogiaemfoco.pro.br. Acesso em 28/o7/2021.

LIMA, L. R. F.; DELMÔNICO, R. L. Estudo Sobre a Importância da Brinquedoteca no Ambiente Escolar como Espaço Mediador de Aprendizagens, sob o Ponto de Vista dos 
Professores da Rede Municipal de Ensino do Cornélio Procópio. Disponível em http://www.pedagogia.com.br. Acesso em: 03/02/2012.

MAFRA, S. R. C. O lúdico e o desenvolvimento da criança deficiente intelectual. Disponível em http://www.diaadiaeducacao.pr.gov.br. Acesso em 28/o7/2021.

MAGAlHÃES, C. M. C.; PONTES, F. A. R. Criação e manutenção de brinquedotecas: Reflexões Acerca do Desenvolvimento de Parcerias. Disponível em: http://www.scielo.br. Acesso em 28/o7/2021.

MATUSHITA, C.K.S.; MENDES, D. M. Jogos e brincadeiras na Educação Infantil. Disponível em http://faculdadesdombosco.edu.br. Acesso em 28/o7/2021.

QUEIROZ, N. L. N. de; MACIEL, D. A. BRANCO, A. U. Brincadeira e desenvolvimento Infantil: um olhar sociocultural construtivista. Disponível em http://www.scielo.br. Acesso em 28/07/2021.

ROJAS, J. Educação Lúdica: a linguagem do brincar, do jogo e da brincadeira no aprender da criança. Campo Grande- MS. Editora: UFMS, 2009.

SIlVA, S. H. C. da; VINÃS, G. N.; CARVAlhO, M. D. B.; PAIVA, C. M. B. de. Brinquedoteca: lugar de brincar e criar. Disponível em http://www.prac.ufpb.br. Acesso em 28/07/2021.

VIEIRA, T. M. A brinquedoteca na Educação Infantil sob um olhar pedagógico. Disponível em http://www.unifan.edu.br. Acesso em 28/o7/2021.

VIGOTSKI, L. S. A formação Social da Mente. Martins Fontes. 2003. 